\title{
Estratégia nacional de ciência, tecnologia e inovação (2016-2019): uma análise das políticas de CTI no Brasil
}

\author{
Arthur Facin De Bortoli ${ }^{1}$ \\ Marlize Rubin Oliveira² \\ Giovanna Pezarico ${ }^{3}$
}

\begin{abstract}
Resumo
O presente trabalho está inserido na área temática de políticas públicas em Ciência Tecnologia e Inovação (CTI) tendo por objetivo, a análise destas, tomando por bojo teórico as discussões acerca da globalização e racionalidade técnico-instrumental. Para o tratamento de tais conceitos, foram trazidos autores como Milton Santos (2001), Boaventura Sousa Santos (1998) e Hélgio Trindade (2013). Pertinente a metodologia, é feita uma análise de conteúdo em cima do documento “Estratégia Nacional de Ciência Tecnologia e Inovação 2016-2019" (de autoria do Ministério da Ciência Tecnologia e Inovação), a qual, por meio da técnica de categorização de Bardin (2011), a categoria "Parceria Público-Privada" foi emergente no processo de análise e, dividida em três subcategorias: pesquisa e atividade científica, empreendedorismo tecnológico, e internacionalização. É nítido no documento o esforço estatal para que exista um constante diálogo entre os institutos de pesquisa e a iniciativa privada. Acreditase que os avanços do país e o alcance do patamar "global" em termos competitivos, se deem muito em função da aplicação das novas tecnologias e conhecimentos produzidos em âmbito científico, na sociedade, e esta aplicação, teria como intermediários os empreendimentos, sobretudo de cunho tecnológico. Todavia, atenta-se para que se pense também nas soluções de problemas locais, e que se criem modelos próprios para tal.
\end{abstract}

Palavras-chave: CTI; Parceria Público-Privada; Globalização.

\section{National science, technology and innovation strategy (2016-2019): an analysis of STI policies in Brazil}

\begin{abstract}
The present work is inserted in the thematic area of public policies in Science Technology and Innovation (CTI), aiming their analisys, taking by theoretical touchstone, the discussions about the globalization and technical-instrumental rationality. For the treatment of such concepts, authors such as Milton Santos (2001), Boaventura Sousa Santos (1998) and Hélgio Trindade (2013) were brought in. Regarding the methodology, a content analysis is made based on the document "National Science Strategy Technology and Innovation 2016-2019" (authored by the Ministry of Science Technology and Innovation), which, using Bardin's categorization technique ( 2011), the "Public-Private Partnership" category emerged in the analysis process and was divided into three subcategories: research and scientific activity, technological entrepreneurship, and internationalization. It is clear to see in the document the state effort for a constant dialogue between research institutes and the private initiative. It is believed that the country's development and the reaching of the "global" level in competitive terms, are due to the social aplication of new technologies and knowledge produced in scientific institutions, having as intermediaries of this aplication, the enterprises, especially the most technological ones. However, it is also very important to think of solutions to local problems, and to create models for them.
\end{abstract}

Keywords: CTI; Public-private partnership; Globalization.

\footnotetext{
1 Bacharel em Administração pela Universidade Tecnológica Federal do Paraná (UTFPR). arthurfacindebortoli@gmail.com

${ }^{2}$ Doutora em Educação. Professora do Programa de Pós-Graduação em Desenvolvimento Regional (PPGDR)/UTFPR. marlize.rubin@gmail.com

${ }^{3}$ Doutora em Tecnologia. Professora do Curso de Administração da Universidade Tecnológica Federal do Paraná (UTFPR).gpezarico@gmail.com
} 


\section{Introdução}

A atuação governamental e a definição de políticas adotadas, sejam no âmbito econômico ou social, impactam diretamente na vida dos cidadãos que de uma forma ou outra são afetados por estas decisões. As políticas públicas emanam do Estado e são concebidas no contexto de uma arena constituída por diferentes atores e recursos. Logo, o Estado caracterizase por ser um "ambiente de sistemática disputa política, não devendo ser compreendido como ente independente da sociedade", como aponta Dias (2011, p. 320). Deste modo depreende-se que a atuação governamental está relacionada com o modo de produção em vigência, neste caso, o modo de produção capitalista. Além disso, partindo do pressuposto de que a conformação da agenda, tomada de decisão, formulação, implementação e avaliação das políticas públicas implicam em efetiva atuação do Estado, compreende-se que estas sofram influências significativas do momento histórico e das relações de poder no qual são produzidas.

Neste sentido, as significativas decorrências da globalização, o crescente fluxo de informações e o acirramento competitivo global, vem provocando profundas alterações nas relações sociais e econômicas. Na atual conjuntura neoliberal, o vetor que baliza o modo como a sociedade está organizada é o capital, que, por meio da informação, produz a "economização e monetarização da vida" (SANTOS, 2001, p. 9).

Assim, a temática de políticas públicas em Ciência, Tecnologia e Inovação (CT\&I) é compreendida no presente estudo como inserida no contexto da globalização. De acordo com Santos (2000, p. 12) “a globalização é, de certa forma, o ápice do processo de internacionalização do mundo capitalista". O autor ainda pondera quanto à racionalidade técnico-instrumental como um dos fatores propulsores da globalização na medida em que "a unicidade da técnica serve de apoio para que se consolide a construção da própria globalização e do capitalismo" (SANTOS, 2001, p. 10). Verifica-se assim, a bricolagem entre o processo globalizante e as relações com a racionalidade hegemônica vigente.

Para Sousa Santos (1988, p.3), que discute esta racionalidade no âmbito científico, tratase de um modelo global e totalitário "na medida em que nega o caráter racional a todas as formas de conhecimento que se não pautarem pelos seus princípios epistemológicos e pelas suas regras metodológicas". Estes princípios metodológicos, de acordo com sua visão, continuam pautados nas ciências naturais, relegando o senso comum e as "humanidades". Dialogando com o objeto de estudo deste artigo estão as relações globais que se dão entre países, sendo que mais caras 
ao intento deste trabalho, as relações compreendidas entre os eixos Norte-Sul e Sul-Sul, sobretudo esta última, que encontra respaldo em Morosini (2011, p.108), a qual defende que:

Embora seja reconhecida a importância da internacionalização norte-sul pelo conhecimento acumulado nos países desenvolvidos, a internacionalização sul-sul, além da solidariedade inerente às relações entre países em desenvolvimento, acarreta o fortalecimento desses blocos, necessário num mundo transnacionalizado.

Assim, é nesse contexto de pesquisa, da compreensão do conceito de globalização hegemônica sustentada na racionalidade técnico-instrumental, que se insere o objeto de estudo deste artigo, qual seja, a análise acerca das políticas públicas de Ciência, Tecnologia e Inovação.

Para tanto, como recorte metodológico, tais análises foram realizadas a partir do documento “Estratégia Nacional de Ciência, Tecnologia e Inovação 2016-2019” (MCTI, 2016). Como condução da pesquisa, realizou-se um estudo documental exploratório e descritivo acerca do tema. De modo sintetizar o texto e facilitar nas referenciações, o documento acima será citado utilizando-se da abreviatura ENCTI (2016). Trabalho similar foi desenvolvido por Junior e Kato (2016), onde os autores tratam do mesmo documento tendo como viés a internacionalização da Educação Superior.

Importa salientar que o documento, conforme consta em seu próprio título, tem seu tempo de vigência estabelecida entre o ano de 2016 até o ano de 2019, período que compreende uma transição no que diz respeito a conjuntura política brasileira, principalmente representado pelo ato de impeachment, da então presidente, Dilma Rousseff, a posse de seu vice-presidente, Michel Temer, ocorrido no ano de 2016, e a eleição de Jair Bolsonaro em 2018.

O artigo está organizado em três momentos distintos. A primeira seção apresenta a metodologia escolhida, fundamentada no método de análise documental relativa ao documento acima mencionado. Na segunda seção são evidenciadas as análises dos resultados, as quais foram realizadas com o auxílio da técnica de análise categorial de Bardin (2011), fazendo, ainda, o uso de quadros síntese. As principais sínteses são retomadas nas considerações finais, bem como os apontamentos para estudos futuros sobre o tema.

\section{Percurso metodológico}

Considerando os objetivos do estudo, o método escolhido foi a análise documental, com base no documento “Estratégia Nacional de Ciência, Tecnologia e Inovação 2016-2019" (MCTI, 2016). Este documento foi escolhido por sua importância no que se refere ao planejamento estratégico do Ministério de Ciência, Tecnologia e Inovação, lançado no final de 2016, que 
intersecta as tratativas deste trabalho e terá influência nas ações e políticas de "desenvolvimento nacional no tange a excelência e inovação, focado na excelência científica e tecnológica" (MCTI, 2016, p. 06).

De modo a compreender os posicionamentos com relação à ciência, tecnologia e inovação, externados no documento, é de suma importância o entendimento quanto à racionalidade contemporânea. Nesse sentido, Andery (2000) argumenta sobre a racionalidade econômica enquanto base motora da sociedade atual, em que se tem na economia o centro de todas as relações sociais. Para a autora, "as relações de trabalho [...] compõe a base econômica de uma dada sociedade" (2000, p. 11), e que implica na determinação das políticas, bem como, no conjunto de ideias existentes em cada sociedade. Assim, busca-se explicitar algumas das estratégias de ciência, tecnologia e inovação, presentes no documento que reforçam a ideia desse engendramento entre as orientações presentes no ENCTI (2016) e as bases econômicas vigentes.

No que diz respeito ao conhecimento humano - uma das formas de produção do ideário humano - Andery (2000, p.13) afirma que sua produção sempre se insere no momento histórico em que ocorre exprimindo as "condições materiais" desde dado momento. Logo, a ciência é histórica e reflete todas as transformações que ocorrem em cada momento, deste modo é possível observar que os direcionamentos propostos no documento, no que diz respeito à ciência, se dão muito em decorrência da racionalidade e do sistema produtivo, presentes no momento histórico de formulação destas diretrizes.

Por sua vez, Dias (2011), analisando mais especificamente as políticas de C\&T, apregoa em favor de uma aproximação entre a ciência produzida e a sociedade de um modo geral, de modo a tencionar o paradigma de uma ciência que compete única e exclusivamente aos cientistas. Estas definições contribuem na justificativa e relevância de se buscar compreender o Documento ENCTI (2016) em análise e o modo como ocorre este diálogo relacional, entre a ciência sendo produzida e sociedade.

Em termos de caracterização, a pesquisa assume o caráter exploratório e descritivo. É exploratória visto que se tem por intuito propiciar um "entendimento mais aprofundado sobre o tema fazer emergir novas hipóteses e construir melhormente as ideias", além de que "admite os moldes de pesquisa documental" (GIL, 2002, p.41). E ao mesmo tempo é descritiva, pois trata de fazer o estudo e relação entre variáveis (GIL, 2002, p.42). Neste caso: Governo e iniciativa privada, majoritariamente, foi uma relação observada no que diz respeito às variáveis encontradas. Esta ideia de variáveis, dialoga com a proposta de categorização de Bardin (2011, p.148), na qual, de acordo com a autora, buscam-se os elementos mais constitutivos do objeto de análise, neste 
caso, as diretrizes do documento, e fazem-se análises comparativas entre estes elementos, os quais a autora denomina como sendo "categorias".

Existem dois tipos de documentos na pesquisa documental, que são os documentos de "primeira mão", que ainda não receberam nenhum tipo de análise, dentre os quais, encontramse documentos oficiais, de órgãos públicos (GIL, 2002, p.46), como é o caso do ENCTI (2016), e os de segunda mão, que, de acordo com o autor, são aqueles que já foram analisados de alguma forma, como relatórios por exemplo.

Para realização da análise pretendida, foi utilizada a análise de conteúdo orientada por Bardin (2011). Nas palavras da autora, a análise de conteúdo é atualmente, "um conjunto de instrumentos metodológicos cada vez mais sutil em constante aperfeiçoamento, que se aplicam a "discursos" extremamente diversificados" (BARDIN, 2011, p.15). Indo além, a análise de conteúdo oscila entre o pragmatismo e a objetividade, sem nuances, assim como, à "fecundidade da subjetividade" (BARDIN, 2011, p.15), destacando deste modo a importância da questão interpretativa e do subjetivo, na análise de conteúdo.

No que diz respeito à técnica para a feitura da análise, a escolhida para o presente estudo aqui foi a categorização. Categorizar é basicamente fazer a "classificação de elementos constitutivos de um conjunto, por diferenciação, e em seguida por reagrupamento segundo o gênero, com os critérios previamente definidos" (BARDIN, 2011, p.147). Pode-se entender o conjunto composto por estes elementos constitutivos como uma categoria encontrada. A estes elementos constitutivos, a autora ainda dá o nome de "unidade de registro", que seriam elementos que possuem características análogas. Nas palavras da autora "as categorias são rubricas ou classes, as quais reúnem um grupo de unidades de registro, sob um título genérico, agrupamento esse efetuado em razão das características comuns destes elementos" (BARDIN, 2011, p.147).

A autora ainda chama a atenção para a relação existente entre a análise de conteúdo com a análise documental, também presente neste. Visto que a análise documental consiste no tratamento primário de um documento, com vistas a "passear de um documento primário para um documento secundário", ou seja, já analisado de acordo coma ótica do pesquisador, é possível de acordo com a autora, associar as classificações feitas na análise documental, com a categorização da análise de conteúdo (BARDIN, 2011, p.51-52). Todavia, a autora (2011, p.52) atenta para o fato de que (dentre outras diferenças) enquanto na análise documental, o esforço analítico é centrado no documento, na análise de conteúdo as mensagens, a comunicação é o foco. 
O mapeamento e o modo como estão organizadas abaixo as seções da análise de resultados, é muito decorrente da técnica de análise escolhida para tratamento dos dados: a categorização - explanada acima - presente na análise de conteúdo de Bardin (2011). O esforço analítico despendido aqui é traduzido e apresentado por meio de categorias de análise, com a categorização a posteriori. As categorias a posteriori, segundo Bardin (2011, p.149), são aquelas que surgem conforme a análise é feita de modo progressivo, sendo que só ocorre a nomenclação final destas, após o término do processo. A autora chama este tipo de categorização de "procedimento por acervo".

Nesse sentido, a categoria central observada neste trabalho é denominada: Parceria Público-Privado, extremamente presente no decorrer de todo o documento. A partir desta, três subcategorias derivaram: 1) Pesquisa e Atividade Científica; 2) Empreendedorismo Tecnológico e; 3) Internacionalização. Cabe falar, que estas subcategorias, estarão grifadas durante o texto, com o propósito de atribuir destaque ou aos seus termos com a redação específica, ou então, a partir dos termos semelhantes, ainda que escritos de forma diferente.

Uma estratégia adotada, foi reduzir a nomenclatura Parceria Público-Privado, para simplesmente Parceria $P-P$, em decorrência da quantia de vezes que o termo aparece no texto da análise de resultados. Para facilitar a leitura e ajudar na assimilação dos resultados, a divisão feita aqui trata de isolar a análise de cada uma das subcategorias, com o auxílio de quadros-síntese de modo a tornar concisas, todas as informações a serem passadas ao leitor e tornar mais palatável, o entendimento da grande categoria encontrada, que é a parceria público-privado.

Nestes quadros, estará à esquerda o nome da subcategoria encontrada, e a direita os descritores, ou seja, palavras-chave que sumarizam a subcategoria em questão e a definem. Bardin (2011, p.52), denomina além de descritores, como sendo índices que possibilitam "classificar os elementos de informação dos documentos, de maneira muito restrita".

Os autores são ainda trazidos de modo a construir um diálogo argumentativo, na medida em que os resultados forem sendo mostrados. Cada subcategoria, representa um subitem na divisão setorial deste capítulo, sendo que os descritores de cada subcategoria, serão tratados de igual modo de forma integrada e corrida, todavia, de modo a facilitar a localização na análise, cada vez que aparecerem, estarão grifados, porém nem sempre com a exata redação anunciada.

\section{A parceria público-privada (PPP)}


A seguir, de modo a iniciar as tratativas analíticas, é apresentado excerto que enfatiza toda a importância no que concerne o papel da parceria entre o setor público e privado, tratado no documento atinente às estratégias no âmbito da Ciência, Tecnologia e Inovação.

[...] os investimentos privados são fundamentais para o desenvolvimento científico e tecnológico, tal como se observa em estatísticas mundiais acerca dos aportes em PD\&I. Evidenciam-se, nesse cenário, que as trajetórias de evolução dos SNCTIs são aquelas que primam pela integração contínua das políticas governamentais com as estratégias empresariais. (MCTI, 2016, p.17).

A categoria pode ser verificada durante todo o documento. É percebido nitidamente o foco no estabelecimento de alianças entre a iniciativa privada e o governo de modo a fazer com que haja estreito diálogo entre as inovações e tecnologias desenvolvidas nos centros de pesquisa e na academia de tal modo a fazer com que se alcance um "enraizamento social da ciência, tecnologia e inovação", devendo ainda, ser "direcionado à solução de questões regionais, fomentando saberes tradicionais, disseminando e difundindo o ensino tecnológico e científico" (MCTI, 2016, p. 94).

Destes "saberes tradicionais", é possível fazer menção à Sousa Santos (1988, p.25), o qual afirma que o paradigma científico emergente não deve ignorar os conhecimentos do senso comum, mas sim aliar-se a ele na tentativa de compreender melhor o mundo e a inserção humana nele. O autor afirma que esta espécie de conhecimento, dentre várias características citadas por ele, superficial, transparente e evidente, mas ao mesmo tempo, tem uma profundidade pragmática no que diz respeito às relações sociais e o modo como as pessoas interagem entre si e com o mundo, arrematando, com o argumento de que é "retórico e metafórico, não ensina, persuade" (SOUSA SANTOS, 1988, p.25).

Já pertinente à "solução de questões regionais", Santos (2001, p.11), vai argumentar em favor de uma globalização mais humana em que se utilize dos recursos técnicos disponíveis, do conhecimento científico disponível neste caso, para que as mudanças ocorram do local para o global, e não o contrário. O autor defende que a grande diversidade de etnias e filosofias de vida, aglomeradas em pontos cria o que ele chama de "sociodiversidade", o que segundo o autor, é um dos fatores mais importantes para que as questões regionais possam ser resolvidas em contraposição à intensa globalização, a qual ele denomina de "perversa".

Ainda, Santos (2001, p.19) argumenta que essa "perversidade" é advinda muito em função da racionalidade econômica e da "competitividade". Já no documento, a competitividade é tratada de forma diferente como se pode observar:

Em um contexto de globalização, as políticas públicas e iniciativas privadas de países em desenvolvimento têm sido orientadas para a conformação de trajetórias de 
emparelhamento baseadas tanto na cooperação como na competição internacional. A trajetória de evolução do SNCTI brasileiro é marcada pela necessidade de emparelhamento do País com os Sistemas mais avançados do mundo. Vultosos investimentos têm sido realizados nos últimos anos com o objetivo de acelerar o desenvolvimento científico e tecnológico nacional, levando o Brasil a se destacar em diversos setores da CT\&I. Os principais atores desse sistema são as ICTs, as entidades da gestão pública e as empresas. (MCTI, 2016, p.17).

No excerto acima, é possível verificar uma vez mais a categoria, Parceria $P$ - $P$ como aspecto recorrente da política estabelecida. Para que o leitor possa se situar, abaixo consta um quadro em que estão listadas à direita as subcategories já mencionadas acima. Vale aqui a explanação de que as subcategorias podem ser concebidas como "descritoras", da Parceria P-P, visto que conseguem de um certo de modo sumarizar os aspectos mais essenciais na composição da categoria.

Quadro 1 - As subcategorias das Parcerias Público-Privado

\begin{tabular}{|c|c|}
\hline \multirow{2}{*}{$\begin{array}{c}\text { Parcerias } \\
\text { público-privado (PPP) }\end{array}$} & PESQUISA E ATIVIDADE CIENTÍFICA \\
\cline { 2 - 2 } & EMPREENDEDORISMO TECNOLÓGICO \\
\cline { 2 - 2 } & INTERNACIONALIZAÇÃO \\
\hline
\end{tabular}

Fonte: dados de pesquisa (2017)

Pode-se também enxergar de outra forma esta relação "hierárquica", verticalizada entre categoria e subcategorias. Levando-se em consideração, que a unidade de registro é uma "unidade de significação codificada que corresponde ao segmento de conteúdo considerado unidade base" (BARDIN, 2011, p.134), e que essa unidade base pode ser tida como unidade de contexto, visto que "serve de unidade de compreensão para codificar a unidade de registro" (BARDIN, 2011, p.137), é possível ainda depreender as subcategorias como sendo unidades de registro, inseridas dentro de sua unidade de contexto (a própria categoria).

\subsection{Pesquisa e Atividade Científica}

A primeira subcategoria a ser discutida é Pesquisa e Atividade Científica. Como dito anteriormente, tal descrição será ilustrada em um quadro síntese (Quadro 2). Para esta subcategoria, os aspectos mais representativos encontrados e que se traduzem em índices analíticos são: Comercialização, Transferência, Atendimento de Demandas e Recurso Humano. Como mencionado acima, os descritores são analisados dentro do texto corrido e por vezes dialogam entre si. 
Quadro 2 - Descritores da subcategoria pesquisa e atividade científica

\begin{tabular}{|c|c|}
\hline \multirow{4}{*}{$\begin{array}{c}\text { Pesquisa e } \\
\text { atividade científica }\end{array}$} & COMERCIALIZAÇÃO \\
\cline { 2 - 3 } & TRANSFERÊNCIA \\
\cline { 2 - 3 } & ATENDEDIMENTO DEDEMANDAS \\
\cline { 2 - 3 } & RECURSO HUMANO \\
\hline
\end{tabular}

Fonte: dados de pesquisa (2017)

A comercialização, primeiro descritor da subcategoria em questão, bem como a própria transferência (segundo descritor), aparece de modo claro e explícito no documento analisado, como pode ser aferido no excerto que segue: "uma das tendências recentes mais fortes nas políticas de CT\&I é a do avanço aos incentivos para a comercialização da pesquisa pública, o que inclui, entre outros, a transferência de conhecimento" (ENCTI, 2016, p. 52).

Contribuindo com as ideias acima, Oliveira e Velho $(2009$, p.27) defendem que a transferência de tecnologia é a vertente que tem ganhado maior destaque no que diz respeito às "várias possibilidades de dispor o conhecimento acadêmico à sociedade", argumentando ainda que, neste enredo, cresce a importância e valorização do "uso do sistema de propriedade intelectual (PI) como mecanismo de regulação desse processo colaborativo, sendo a patente a sua forma mais conhecida".

É argumentado ainda, que tais medidas, renderiam receitas à universidade, além de que seria possível por meio da transferência do conhecimento, fazer chegar às empresas, sobretudo de base inovadora, os avanços tecnológicos produzidos em âmbito acadêmico e nos demais institutos de pesquisa (ENCTI, 2016). Esta sistemática, segundo Oliveira e Velho (2009, p.28) "têm valorizado o papel da universidade no que se refere à sua função social ligada à produção e transferência do conhecimento para a sociedade", contribuindo ainda para o "encurtamento do ciclo de inovação tecnológica e crescente incorporação dos conhecimentos científicos na base do progresso técnico" (OLIVEIRA; VELHO, 2009, p.28).

No entanto, como evidencia Santos (2001, p.9) ao atentar para a racionalidade econômica que move as relações, o autor argumenta que os fundamentos do mundo em que vivemos estão galgados em servir ao "império do dinheiro" e na "monetização da vida". Deste modo é possível compreender a comercialização da pesquisa como sendo mais um desdobramento do que teoriza o autor. $\mathrm{O}$ autor ainda adverte para o fato de que essa relação pode acabar subsidiando a mais-valia moderna. Em suas palavras, "A atual competitividade entre 
as empresas é uma forma de exercício dessa mais-valia" sendo estreitada ainda mais pelas demandas por inovações tecnológicas (SANTOS, 2001, p.15).

O terceiro descritor já se mostra presente neste mesmo trecho, quando se pode interpretar que o que acaba existindo com forte presença, são anseios dos segmentos empresariais pelas tecnologias que estão sendo desenvolvidas nos institutos de pesquisa, o que denota uma demanda a ser atendida. O documento é favorável quanto a esta relação, argumentando que de modo a estreitar ainda mais a "colaboração em PD\&l entre academia e indústria", se "aprimore o arcabouço legal e institucional" (ENCTI, 2016, p. 52).

No excerto acima, observa-se nitidamente a Parceria P-P. Corroborando com este ponto, Trindade (2013) afirma que esta forte relação Público-Privado é justamente formatada como decorrência dos rápidos avanços científicos e tecnológicos da sociedade atual, somada às demandas por inovações. Tomando como exemplo as relações entre Universidade e setor produtivo, com a comercialização de pesquisa e afins, Oliveira e Velho $(2009$, p.48) chamam atenção para o fato de que por mais que reste estimulada esta aproximação entre o público e o privado, "não estão previstos mecanismos que reflitam uma preocupação concreta com o monitoramento dos impactos deste processo na universidade".

Em se tratando da discussão das demandas por inovações, suscitada por Trindade (2013), cabe destacar e explanar o real significado de Inovação, e este, é trazido por Schumpeter (1997) que, ao creditar os avanços da sociedade o qual afirma que aquela, para ser assim caracterizada, deve ser economicamente relevante, o que significa dizer que deve ser sentida no mercado, afastando-se, deste modo, de uma mera invenção que não chega a gerar efeitos práticos e mercadológicos.

Focando mais especificamente no que concerne o terceiro descritor da subcategoria, que é o atendimento de demandas, é percebido no Documento a convicção que se tem sobre a pesquisa, para que se possam ter supridos os anseios da sociedade em relação à sustentabilidade e inclusão:

Todos convergem ao entendimento de que a pesquisa é um investimento fundamental para a prosperidade de nossos descendentes, para o desenvolvimento sustentável e inclusivo e para a melhoria da qualidade de vida dos brasileiros (ENCTI, 2016, p.6).

Nesse sentido, é importante considerar também como demandas, as perspectivas relacionadas no contexto do desenvolvimento sustentável e do desenvolvimento para além do crescimento econômico. Logo, não se pode considerar apenas o atendimento das demandas do mercado e de setores produtivos tradicionais. Neste aspecto, as discussões produzidas no âmbito 
da relação entre Ciência, Tecnologia e Sociedade podem auxiliar na conformação das agendas relativas aos conhecimentos a serem produzidos.

Trazendo agora para o diálogo entre a Parceria $P-P$ e a pesquisa e a atividade científica, é possível inferir que no documento orientador, privilegia-se a elaboração de novas tecnologias e aplicação no setor produtivo, bem como, a geração de empregos, concebidas como pilares para o desenvolvimento do país, implicando em condições favoráveis à qualidade de vida, como é explicitado no trecho que segue onde também é verificado o atendimento de demandas:

Ao estimular novas oportunidades de inserção socioprodutiva, geração de emprego e renda, a CT\&I também contribui para a qualidade de vida no meio urbano, no desenvolvimento de novos métodos e técnicas que atendam demandas sociais, especialmente nas áreas de educação, saúde, habitação, segurança, mobilidade urbana e energia (ENCTI, 2016, p.95, grifo nosso).

É possível compreender que o caminho assumido para o desenvolvimento neste caso, enunciado pelo Documento no trecho acima, divide a mesma rota a partir das transformações tecnológicas e aplicação de caráter social desta tecnologia. Com isto vale ressaltar mais uma vez a importância do diálogo e da Parceria $P$-P de modo a fazer com que esta produção de inovações consiga efetivamente chegar a sociedade como um todo. Corroborando com a importância da inovação tecnológica - e consequentemente da pesquisa científica, que possibilita isto - é exposto o excerto a seguir:

Para atender a população ainda marginalizada da oferta desses serviços e que vive em condições precárias nas cidades brasileiras, é necessário desenvolver e difundir tecnologias que sejam adequadas às características econômicas, sociais e de urbanização do país (ENCTI, 2016, p.95).

Dialogando com os dizeres acima, Trindade (2013, p. 36), atenta para a importância de a produção científica de fato espraiar para a Sociedade, e não ficar somente no âmbito acadêmico. A Universidade tem papel de formação identitária de uma nação, deste modo, deve ser vista como extensão da própria sociedade e não como algo externo a ela (TRINDADE, 2013, p.36).

Tratando ainda da Parceria P-P, de acordo com Trindade (2013), não só a pesquisa, como a Educação Superior de um modo geral, acaba se fazendo reflexo das imposições de um mundo fortemente globalizado. É possível classificar a demanda por novas tecnologias e inovações, como uma imposição e mais que isso, um anseio deste modelo global. Ainda é possível entender deste modo, o quão necessário são Pesquisa e Atividade Científica de modo que se possam desenvolver novas tecnologias que sejam aplicadas na sociedade por intermédio do setor produtivo. 
Entretanto, há de se considerar que a competitividade, como afirma Santos (2001, p.15), “torna exponencial a briga entre as empresas e as conduz a alimentar uma demanda diuturna de mais ciência, de mais tecnologia, de mais organização, para manter-se à frente da corrida".

No que concerne o papel dos pesquisadores de fato, o Documento aponta que "Os países mais inovadores e competitivos são também aqueles nos quais é maior o investimento em formação e capacitação de recursos humanos de modo continuado" ( MCTI, 2016, p.8).

No trecho acima, pode-se observar ainda o foco global, tendo como espelho as nações mais inovadoras e competitivas, neste caso. Este ponto dialoga perceptivelmente com a subcategoria Internacionalização, que será analisada minunciosamente mais à frente.

É ainda argumentado, quanto à importância dos Recursos Humanos na pesquisa, que o desenvolvimento de projetos inovadores e de "pesquisas pioneiras", começam pelo aperfeiçoamento da mão de obra e pela formação de pesquisadores qualificados que estejam de fato "comprometidos com o conhecimento" (ENCTI, 2016, p.8). O interesse com a formação dos pesquisadores pode ser auferido quando se alega que é "preciso atrair os jovens para as carreiras científicas e, ao mesmo tempo, aumentar os níveis da educação científica da população em geral” (ENCTI, 2016, p. 95).

Ante o exposto, percebe-se o quão caro são para o documento, os elementos Pesquisa e Atividade Científica e o quanto ilustram as vinculações privilegiadas no documento orientador entre a relação entre as instituições dedicadas à pesquisa de fato e os setores produtivos.

\subsection{Empreendedorismo Tecnológico Inovador}

Neste item, iniciam-se as considerações que dizem respeito à análise da segunda subcategoria encontrada: O Empreendedorismo Tecnológico/Inovador. Seguindo o raciocínio e organização vistos acima, nas tratativas da primeira subcategoria, segue abaixo, um quadro síntese composto pelos descritores da subcategoria em questão.

Quadro 3 - Descritores da subcategoria empreendedorismo tecnológico/inovador

\begin{tabular}{|l|c|}
\hline $\begin{array}{l}\text { Empreendedorismo } \\
\text { tecnológico/inovador }\end{array}$ & COLABORAÇÃO E INTEGRAÇÃO \\
\cline { 2 - 2 } & DESENVOLVIMENTO E AVANÇOS \\
\hline
\end{tabular}

Fonte: dados de pesquisa (2017) 
No que tange o primeiro descritor, colaboração e integração, um dos trechos que mais marca tal aspecto, senão o mais marcante é transcrito a seguir. O referido trecho encontra-se logo no início do documento, onde é citada e lei 13.243/2016, que argumenta:

\begin{abstract}
Movidos pelo anseio de modernização da estrutura legal que regia as práticas de CT\&I no País e somando a necessária regulamentação legal [...] reduziu entraves burocráticos enfrentados nas atividades de pesquisa científica, além de admitir novas possibilidades de articulação entre as atividades inovadoras empresariais e as infraestruturas laboratoriais e de recursos humanos presentes nos institutos públicos de pesquisa (MCTI, 2016, p.7, grifo nosso).
\end{abstract}

A parte grifada do texto reforça o direcionamento do documento no que diz respeito ao empreendedorismo de um modo geral. Todavia, é evidente o zelo tratado acima no que diz respeito aos empreendimentos que buscam inovar, utilizar-se de novas tecnologias. $\mathrm{E}$ isto se torna possível, conforme excerto acima, mediante a colaboração e o estreitamento das relações entre empreendedores com as estruturas públicas especializadas em pesquisa. Além de ilustrar a subcategoria em estudo, uma vez mais facilmente verificada a Relação $P$ - $P$, entre laboratórios (públicos) e empreendimentos (privado).

Outro trecho que auxilia na explanação da categoria e o modo como ela está presente no documento, é tratada quando se fala sobre uma "tendência recente nas políticas de CT\&I ao redor do mundo", tendência essa, chamada de "inovação aberta ou open innovation". O intuito deste "modelo de inovação altamente colaborativo" é o de facilitar a ocorrência desta relação entre empreendedores e institutos públicos de pesquisa, por meio de intermediários “responsáveis por atividades desde o preenchimento de lacunas de informação até a criação de espaços que favoreçam as interações entre indivíduos e organizações, identificando potenciais colaboradores" (MCTI, 2016, p.54).

Agregando à discussão, Martins et al., (2014, p.86) defendem que o empreendedorismo, bem como a inovação "passaram a ser considerados fatores fundamentais na busca pela competitividade das organizações, sobretudo nos setores em que a tecnologia é elemento determinante para a vantagem competitiva", coadunando com a inclinação pró empreendimentos inovadores, trazida pelo ENCTI (2016).

Há ainda o destaque ao papel cooperativo de pesquisadores e a relação com os incentivos que devem ser feitos as empresas de base tecnológicas nascentes (MCTI, 2016, p.65). A imprescindibilidade desta relação pública (pesquisadores e institutos científicos) e privada (empresas de base tecnológica) é explicitada também pela necessidade de regulação destas relações e a "melhoria do ambiente institucional para os negócios inovadores" (MCTI, 2016, p.65). 
Da mesma forma, a existência de empreendimentos de base tecnológica e sua importância são externadas no trecho a seguir, onde se iniciam as tratativas do segundo descritor da subcategoria em questão, desenvolvimento e avanços.

A criação de ambientes cooperativos controlados para empresas de base tecnológica posiciona o País em situação promissora, especialmente quando estamos próximos de comemorar mil empresas instaladas nos 30 Parques Tecnológicos em operação (MCTI, 2016, p.7, grifo nosso).

É ainda arrazoado em favor de uma "cultura de ciência e inovação", onde se estimule "tanto o empreendedorismo como a criatividade por meio de diversas iniciativas como a realização de grandes eventos públicos, promoção de campanhas, competições e premiações". Mais uma vez, vale o destaque ao empreendedorismo inovador, junto à competição, característica marcante das fortes condições de globalização mundiais.

Há de se notar também, o diálogo existente entre os descritores desta subcategoria, algo que é nítido, onde é referido no Documento que é de fundamental importância, "estimular a articulação (colaboração e integração) entre o setor empresarial e as universidades e centros de pesquisas, com o intuito de fortalecer o empreendedorismo inovador e os seus impactos em termos de desenvolvimento (desenvolvimento e avanços) regional" (MCTI, 2016, p.80).

Interessante notar o foco que se tem ao final do excerto acima, quando é tratada da questão do desenvolvimento regional, diferindo do "espelho global" adotado na maior parte do documento, o que outra vez, remete aos dizeres de Santos (2001, p.11) e a importância de se pensar no local e nas questões mais regionais em contraposição com o padrão global que cada vez mais é difuso e abrangente.

Fica novamente perceptível a Parceria $P$-P presente nesta relação entre o segmento privado empreendedor e os institutos especializados em pesquisa. Conforme o documento, os empreendimentos de base tecnológica, facilitados pela adesão às tecnologias descobertas nos referidos institutos, cumprem um papel importante: o de "fazer chegar" a sociedade geral o que é produzido e desenvolvido nos laboratórios, um forte traço colaborativo capaz de alavancar avanços, como foi possível auferir nos trechos analisados.

Referente a estes avanços, Oliveira (2004) preconiza a importância da crescente preocupação do setor produtivo e participação no campo social. Com isso, abstrai-se que o desenvolvimento tecnológico científico não atenda somente ao mercado, mas também a outros anseios não mercadológicos. 


\subsection{Internacionalização}

É importante destacar, que a internacionalização, é representada no documento analisado como um "parâmetro global", que visa, por exemplo, "seguir as tendências globais em CT\&I". Por esta razão, o terceiro descritor encontra-se destacado, pois ele vai acabar permeando praticamente todas as discussões que serão feitas nesta subcategoria.

Quadro 4-Descritores da subcategoria Internacionalização

\begin{tabular}{|l|l|}
\hline \multirow{2}{*}{ Internacionalização } & COMPETIÇÃO \\
\cline { 2 - 2 } & COOPERAÇÃO \\
\cline { 2 - 2 } & FOCO GLOBAL \\
\hline
\end{tabular}

Fonte: dados de pesquisa (2017)

Em relação a este aspecto, é apresentado o primeiro descritor da subcategoria: a Competição. Esta questão é fortemente observada no trecho a seguir, onde se percebe o foco global e a competição, presentes no mesmo excerto:

Em um contexto de globalização, as políticas públicas e iniciativas privadas de países em desenvolvimento têm sido orientadas para a conformação de trajetórias de emparelhamento baseadas tanto na cooperação como na competição internacional (MCTI, 2016, p.17, grifo nosso).

Voltando-se mais amplamente ao papel da CT\&I, é averiguado que de acordo com o Documento:

Somente com uma população que se aproprie de maneira plena e sustentável da CT\&I que o País poderá se firmar como uma nação soberana e em condições de interagir com o cenário internacional contemporâneo (MCTI, 2016, p.55, grifo nosso).

Entretanto, é intrigante o quanto a palavra interagir, negritada acima, bem como toda a frase que a contextualiza, pode tratar dos três descritores desta subcategoria, simultaneamente. Esta "interação", pode se referir a um contato enquanto possibilidade de alianças e trocas cooperativas, bem como possibilidade de competir com os produtos e tecnologias desenvolvidas internacionalmente, sendo que tais aspectos demostram a preocupação em conseguir relevância internacional.

Quando se trata do descritor cooperação, um trecho no Documento deixa particularmente clara a imprescindibilidade desse requisito, ao apontar que "A cooperação científica internacional também é essencial de modo a mobilizar competências no Brasil e no exterior, contribuindo para a qualificação de pessoas e para a promoção de PD\&l" (MCTI, 2016, 
p.79). Ao se falar da "qualificação de pessoas", aparece aqui uma relação dialógica com o descritor Recurso Humano, na subcategoria Pesquisa e Atividade Científica.

A este respeito, Morosini (2011) traz importantes apontamentos, explicando como a interação e a referida qualificação de recursos humanos normalmente ocorrem, arrazoando que

\begin{abstract}
a cooperação internacional inicial, via de regra, começa com a capacitação no exterior de professores e alunos de doutorado, que, no decorrer de sua vida acadêmica, estabelecem laços [...] com seus pares e respectivos departamentos universitários ou centros de pesquisa onde estagiaram (MOROSINI, 2011, p.98).
\end{abstract}

Vale menção, no que tange Internacionalização, e sua relação com a subcategoria Pesquisa E Atividade Científica, os indicadores relativos ao programa Ciência Sem Fronteiras ${ }^{4}$, responsável pelo intercâmbio de alunos da graduação e pós graduação, das universidades brasileiras. $\mathrm{O}$ destaque fica por conta de que a maior parte dos estudantes que faziam uso deste programa, tinham como destino os "Países do Norte", evidenciando o foco global, conforme mostrado a Figura 1.

Figura 1 - Bolsas de estudo do Programa Ciência sem Fronteiras

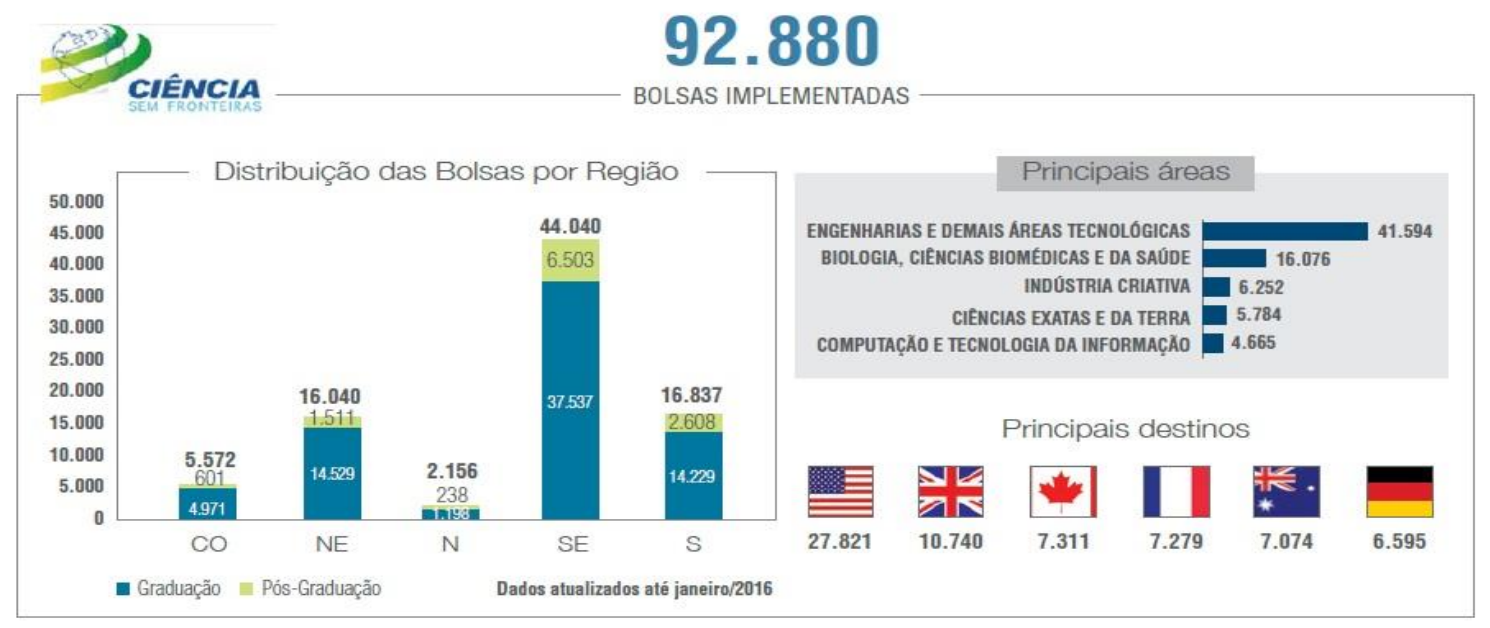

Fonte: MCTI (2016, p.38)

Um outro posicionamento contido no documento que evidência o enfoque global, desta vez, enquanto meio para solução de problemas locais, pode ser vislumbrado na sequência, em que é dito que "[...] o desenvolvimento da CT\&l brasileira exige o reconhecimento de que problemas identificados em escala nacional podem contar com soluções construídas em escala global" (MCTI, 2016, p.63).

Tencionando tal discussão a partir de outro ponto de vista, Santos (2001, p.17) vai atentar para as precauções necessárias frente ao "pensamento único", ao argumentar que a

\footnotetext{
${ }^{4}$ Programa que já não mais possui edital aberto.
} 
utilização de processos hegemônicos mesmo em realidades não hegemônicas tende a extinguir as especificidades do local, e que essa padronização de processos não é benéfica para a realidade local, muito em função de que "os resultados localmente obtidos são menores".

Contudo, ao analisar o último descritor, o foco global, encontra-se no documento um trecho (MCTI, 2016, p.66) em que é comentado quanto a uma lei de inovação que facilita "a atuação do Estado no estímulo aos negócios inovadores". Todavia o que mais se destaca, pertinente a este descritor, vem na sequência, onde é argumentado que "essas mudanças normativas demonstram que o País acompanha a tendência internacional de melhoria das condições institucionais para o desenvolvimento da CT\&I." (MCTI, 2016, p.66).

Interessante notar ainda com relação à lei citada, uma vez mais a tentativa de estreitamento e facilitação na atuação entre Estado e o Empreendedorismo privado, sendo que essa é uma questão que vem ocorrendo em escala global, o que só comprova o fato de o enfoque global estar presente uma vez mais também nessa relação entre governo e empreendimentos inovadores, que não deixa por si só, de ser uma Relação $P$-P.

No que diz respeito ainda à vista global, uma outra relação é possível de ser observada, ao se analisar a fala onde é dito que o "Brasil tem investido na expansão do sistema universitário e modernização dos institutos públicos de pesquisa", a vista global está presente quanto é afirmado que os investimentos foram fundamentais para a formação de "cientistas e grupos de pesquisa de nível internacional" (MCTI, 2016, p.75).

A referida formação de cientistas e grupos de pesquisa de nível internacional é um traço marcante da globalização da educação superior, a qual, segundo Morosini (2011, p.94) é um "conceito complexo [...] que, similar a outros fatos sociais, sofre interferência de tempo e espaço".

Percebe-se claramente o enfoque global na formação de cientistas qualificados. Desse modo, conforme o documento, é que se consegue produzir um conhecimento de maior relevância e de maior qualidade. Vê-se então, o foco em obter-se o "nível mundial", dialogando com Pesquisa e Atividade Científica, a primeira das subcategorias analisadas, e o descritor Recurso Humano.

No documento também são utilizados argumentos favoráveis a um desenvolvimento científico e tecnológico relacionado diretamente com o "desenvolvimento socioeconômico das nações". Além disto, pode-se verificar no mesmo trecho, que:

Posicionar o Brasil entre os países de maior destaque na CT\&I mundial é um grande desafio, que poderá ser alcançado apenas quando houver avanços significativos nas áreas prioritárias indicadas nesta Estratégia (MCTI, 2016, p.63, grifo nosso). 
O que reafirma o posicionamento no Documento quanto ao esforço de internacionalização, onde se diz ser possível alcançar um posto entre as nações mais desenvolvidas no que tange a CT\&I, se forem seguidas as disposições e estratégias presentes no Documento.

\section{Considerações finais}

O presente artigo teve por objetivo, identificar e analisar, no bojo das políticas de ciência e tecnologia, as premissas e orientações presentes no documento "Estratégia Nacional de Ciência, Tecnologia e Inovação 2016-2019", considerando como aspectos da análise as categorias :Parceria Público-Privado, da qual derivaram as subcategorias: Pesquisa e Atividade Científica, Empreendedorismo Tecnológico e, Internacionalização.

Como apresentado na Introdução, o documento estratégico que serviu como base analítica deste trabalho, denominado no estudo de ENCTI, compreende um período de vigência que se iniciou em 2016 e irá se estender até 2019. Este período é singular para o cenário político brasileiro, considerando impeachment e as alterações não apenas no âmbito presidencial, mas nos escalões responsáveis por tais políticas. Além disso no mesmo período, acontecerá mais um processo eleitoral em 2018. Toda esta contextualização conjuntural, permite considerar que o período atual é envolto em incertezas e as proposições contidas na estratégia, podem sofrer influência desta conjuntura.

Partindo mais para a análise realizada, pôde-se perceber que a relação que envolve de maneira mais presente, todas as propostas estratégicas contidas no documento, é a parceria público-privado, que fora tratada no documento como sendo de grande importância e recorrência, constituindo a categoria analítica em questão.

É nítido e presente no documento o esforço estatal para que exista um constante diálogo entre os institutos de pesquisa e a iniciativa privada. Acredita-se que os avanços da nação como um todo, se deem muito em função da aplicação das novas tecnologias e inovações produzidas em âmbito científico, na sociedade, e esta aplicação, teria como intermediários os empreendimentos. Assim, é vislumbrado também o enorme interesse demonstrado no documento por empreendimentos tecnológicos, o que ressalta a ideia de que o desenvolvimento da nação se pauta também, em um setor tecnológico robusto e que esteja a par das novas tecnologias desenvolvidas nos institutos de pesquisa. 
Diante disto tudo, a educação tem um papel fundamental, sobretudo em relação à Educação Superior e a Pós-Graduação, que são os níveis onde ocorrem de fato as pesquisas tão fundamentais para os avanços científicos e, tecnológicos. A cooperação internacional é tratada como sendo de grande importância para que se "multiplique o conhecimento adquirido". Isto seria alcançado, de acordo com o documento, por meio do intercâmbio de pesquisadores em países desenvolvidos, para que estes possam se aprimorar.

É ainda argumentado no documento, em favor da apropriação de toda a nação, de ciência e tecnologia. É necessário que seja desenvolvido um espírito científico de certa forma, e isto é conseguido, por meio do incentivo a formação extensiva de pesquisadores, para que seja criada uma conjuntura favorável a cooperação internacional,

Todavia, o foco no que tange a internacionalização da educação superior se dá de duas formas. No que concerne aos cursos, a prioridade são cursos vinculados às áreas consideradas estratégicas com foco nas Ciências Exatas, como engenharia e demais áreas tecnológicas. O outro foco, diz respeito aos destinos considerados privilegiados para as ações de cooperação, com predominância para as nações do Norte, sobretudo os Estados Unidos.

Mediante tal situação, é possível deduzir que se o interesse também é a "solução de questões regionais", como de fato é, é importante que sejam fomentadas cooperações com as nações vizinhas, nações do Sul, de modo a "criar modelos próprios" para a resolução destas regionalidades, pensando não só do modo "global" como é externado no documento, mas dando também o devido valor para as localidades.

\section{Referências}

ANDERY, M. A. Et al. Para compreender a ciência: uma perspectiva histórica. 9a edição. Rio de Janeiro: Espaço e Tempo: 2000. p. 9 - 15.

BARDIN, L. Análise de Conteúdo. 1ạ edição, Brasil: Edições 70 - BRASIL, 2011, 280 p.

DIAS, R.B. O que é a Política Científica e Tecnológica?.Sociologias, Porto Alegre, ano 13, nำ28, 2011, p. 316-344.

GIL, A. C. Como Elaborar Um Projeto de Pesquisa. 4a edição, São Paulo: Editora Atlas S. A., 2002, $176 \mathrm{p}$.

JUNIOR, J. R. S.; KATO, F. B. G. A Política de Internacionalização da Educação Superior no Plano Nacional de Pós-Graduação (2011-2020). Campinas, SP, Vol.2, n.1, 2016, p. 138-151.

MARTINS, C. et al. Empreendedorismo inovador gerado pelas incubadoras de base tecnológica : mapeamento da produção científica até 2013. Revista de Negócios, v. 19, n. 2, p. 86-108, 2014. 
MINAYO, M. C. De. S. O Desafio do Conhecimento: Pesquisa Qualitativa em Saúde. 14ạ edição, São Paulo, Hucitec, 2014, p. 171-199.

MINISTÉRIO DA CIÊNCIA TECNOLOGIA E INOVAÇÃO (MCTI). Estratégia Nacional de Ciência, Tecnologia e Inovação 2016 - 2019. Disponível em: <http://www.mcti.gov.br/noticia//asset_publisher/epbV0pr6elSo/content/mcti-lancaestrategia-nacional-de-ciencia-tecnologia-einovacao-2016-2019>. Acesso em: 20 novembro de 2016.

MOROSINI, M. C. Internacionalização na produção de conhecimento em IES Brasileiras: cooperação internacional tradicional e cooperação internacional horizontal. Educ. rev. [online]. 2011, vol.27, n.1, pp.93-112.

OLIVEIRA, R. M. DE; VELHO, L. Benefícios e riscos da proteção e comercialização da pesquisa acadêmica: uma discussão necessária. Ensaio: aval. pol. públ. Educ, v. 17, n. 62, p. 25-54, 2009.

OLIVEIRA, E. M. Empreendedorismo social no Brasil : atual configuração, perspectivas e desafios - notas introdutórias. Revista da FAE, v. 7, n. 2, p. 9-18, 2004.

RICHARDSON, R. J. Et al. Pesquisa Social: Métodos e Técnicas. 3ạ edição, 11a reimpressão, São Paulo, Editora Atlas S. A., 2010, 334 p.

SANTOS, M. Por Uma Outra Globalização: Do Pensamento Único à Consciência Universal. 5ạ edição, Brasil: Record, abril de 2001. 174 p.

SCHUMPETER, J. A. Teoria Do Desenvolvimento Econômico - Uma Investigação Sobre Lucros, Capital, Crédito, Juro e O Ciclo Econômico. São Paulo - SP: Editora Nova Cultural, 1997.

SOUSA SANTOS, B. Um Discurso Sobre As Ciências Na Transição Para Uma Ciência Pós-Moderna. Estud. av., São Paulo, v. 2, n. 2, p. 46-71, Aug. 1988. Disponível em:

$<$ http://www.scielo.br/scielo.php?script=sci_arttext\&pid=S0103-

40141988000200007\&lng=en\&nrm=iso >. Acesso em:

07 mar. 2017. http://dx.doi.org/10.1590/S0103-40141988000200007

TRINDADE, H. Por un nuevo proyecto universitario: de la "universidad en ruínas" a la "universidad emancipatoria". Revista do IMEA-UNILA, 2013, 46 p. 